\title{
A INTERDISCIPLINARIDADE NAS UNIVERSIDADES BRASILEIRAS: TRAJETÓRIA E DESAFIOS
}

\author{
INTERDISCIPLINARITY IN BRAZILIAN UNIVERSITIES: TRAJECTORY \\ AND CHALLENGES
}

\author{
Elvio Quirino Pereira \\ Universidade Federal do Tocantins - Palmas - TO - Brasil \\ Elimar Pinheiro do Nascimento \\ Universidade de Brasília - Brasília - DF - Brasil
}

\begin{abstract}
Resumo: Uma reflexão acerca da trajetória e das práticas interdisciplinares recentes nas universidades brasileiras e seus desafios é o objeto deste artigo. Parte do conceito da interdisciplinaridade, diferenciando-o dos conceitos de multidisciplinaridade, pluridisciplinaridade e transdisciplinaridade. Em seguida, apresenta a evolução dos debates e as reflexões precursoras de Georges Gusdof, na França, e Hilton Japiassu e Ivani Fazenda, no Brasil; descreve as etapas do processo histórico dos cursos de pós-graduação interdisciplinares. Ressalta, ainda, o papel precursor de alguns pesquisadores que fomentaram a criação do Comitê da Área Multidisciplinar da Coordenação de Aperfeiçoamento de Pessoal de Nível Superior - CAPES e que, posteriormente, transformou-se em Interdisciplinar. Aborda as dificuldades encontradas para o estabelecimento dos primeiros critérios para o funcionamento e institucionalização do Comitê de interdisciplinaridade e, em seguida, apresenta os dados quantitativos do seu crescimento vertiginoso na pós-graduação, com destaque para a evolução do número de cursos, alunos, bolsas e docentes, assim como, mais recentemente, o surgimento de cursos interdisciplinares na graduação, e seu rebatimento regional. Conclui com a apresentação de alguns dos principais desafios e problemas à prática interdisciplinar na pesquisa e ensino nas universidades em todo o país.
\end{abstract}

Palavras-Chave: Interdisciplinaridade. Pesquisa. Ciência. Pós-graduação. Universidade.

Abstract: The purpose of this study is to promote a reflection about the interdisciplinary practices, trajectory and challenges on Brazilian universities. The text begins by describing the concept of interdisciplinarity, establishing its difference from the concepts of multidisciplinarity, pluridisciplinarity and transdisciplinarity. It presents the evolution of debates and the precursory ideas of Georges Gusdof in France and Hilton Japiassu and Ivani Fazenda in Brazil. It describes the historical process of the interdisciplinary graduating courses. It also highlights the leading role of some researchers that have fostered the creation of the multidisciplinary area of CAPES Committee which subsequently became the interdisciplinary area. It discusses the difficulties found in establishing the first criteria for the operation and institutionalization of the interdisciplinarity Committee, the quantitative data from the vertiginous growth in interdisciplinarity, with emphasis on the evolution on the number students, scholarships and professors, as well as the more recent increase in interdisciplinary graduation courses. It finishes with some of the main challenges and problems to the practice of interdisciplinary research and teaching.

Keywords: Interdisciplinarity. Research. Science. Graduating. University

\section{INTRODUÇÃO}

A interdisciplinaridade vem ganhando um grande espaço nos debates acadêmicos, desde a década de 1970, com a realização de Seminários Internacionais e atividades diversas nas Universidades, Institutos de Pesquisa e Organismos internacionais, entre outros, sob o patrocínio da Organização das 
Nações Unidas para a Educação, a Ciência e a Cultura - UNESCO e Organização para a Cooperação e Desenvolvimento Econômico - OCDE. Juntos, realizaram a publicação de um importante relatório fruto do seminário internacional realizado em 1970 pelo Centre de Recherche et Innovation dans L'Enseignement - CERI. O referido evento teve por objetivo abordar a problemática da Interdisciplinaridade nas Universidades. Nesse seminário, foram discutidos, entre outros temas, a terminologia e as abordagens conceituais utilizadas por diversos pesquisadores, dentre eles Jean Piaget (Suíça), Leó Apostel (Bélgica), Erich Jantch (Áustria), Marcel Boisot (França) e Heinz Heckausen (Alemanha). Analisou-se também resultados de pesquisas em universidades europeias relativas às atividades de interdisciplinaridade na área do ensino e da pesquisa.

No caso brasileiro, o avanço da temática sobre a interdisciplinaridade ocorreu de maneira mais gradativa e, mais tardiamente, por iniciativa da própria comunidade acadêmica, mais especificamente por meio de Programas de PósGraduação. Em 1999, em resposta a esse movimento, a CAPES criou, por sugestão de alguns renomados pesquisadores, o Comitê Multidisciplinar que, em 2008, em meio a um crescente debate em torno das práticas e conceitos de interdisciplinaridade, passou a se denominar Interdisciplinar. O referido Comitê vem cumprindo seu objetivo de apoiar e realizar a avaliação e parametrização das propostas dos cursos de pós-graduação interdisciplinares ao orientar os novos cursos.

O presente artigo visa contribuir para esse debate a partir da realização de uma análise da trajetória da prática interdisciplinar nas universidades, nas agências de fomento e nas políticas públicas de educação do governo federal. Para tanto, são apresentados aspectos conceituais das práticas interdisciplinares adotadas pelos cursos de pós-graduação, buscando demonstrar o crescimento intensivo desse tema a partir de dados que evidenciam a elevação numérica dos cursos, alunos e docentes.

Como resultado do crescimento intensivo da interdisciplinaridade no ensino superior brasileiro, o estudo descreve, também, os seus desafios, visto que ainda permanecem muitas dúvidas e interrogações nas universidades, agências de fomento e na própria comunidade acadêmica. Com o objetivo de subsidiar os debates, o artigo ainda sinaliza a existência de um leque de questões, visões e abordagens ainda divergentes para serem resolvidas.

\section{A interdisciplinaridade e seus similares}

A mudança do Comitê Multidisciplinar para Interdisciplinar na CAPES, em 2008, tem razão de ser, pois há diferenças entre multidisciplinaridade (ou pluridisciplinaridade) e interdisciplinaridade, e mais ainda com a transdisciplinaridade, que não podem ser esquecidas.

Para Piaget, o termo interdisciplinaridade deve ser utilizado quando existir " uma colaboração entre disciplinas diversas ou entre setores heterogêneos de uma mesma ciência que conduz a interações propriamente ditas, isto é, a certa reciprocidade nas trocas, de tal modo que haja um total enriquecimento mútuo" (PIAGET, 1973, p. 142). De acordo com o epistemólogo suíço, a forma mais simples de estabelecer essa ligação interdisciplinar é a percepção do isomorfismo entre as estruturas das diferentes disciplinas em diálogo, ou seja, quando 
especialistas de dois campos diferentes percebem que suas análises acabam por revelar estruturas semelhantes, e o detalhe dessas análises, em um desses campos, pode ajudar a compreender melhor a outra. Assim, a busca desses isomorfismos, o fundamento comum que atravessa as diferentes disciplinas em diálogo, é um dos instrumentos metodológicos mais ricos da interdisciplinaridade.

Por sua vez, a multidisciplinaridade diferencia-se da interdisciplinaridade, pois no primeiro caso as disciplinas são colocadas lado a lado, sem real integração entre elas (REPKO, 2008). Cada disciplina realiza sua leitura e passa a outra, sem que haja maior interlocução e apropriação de aspectos metodológicos que podem se tornar comuns. Essa é, de fato, a definição praticamente consensual entre diversos estudiosos da multidisciplinaridade. Aliás, a CAPES entende por multidisciplinar "o estudo que agrega diferentes áreas do conhecimento em torno de um ou mais temas, no qual cada área ainda preserva sua metodologia $e$ independência" (BRASIL/CAPES, 2013, p. 12). Nesse sentido, mesmo de forma limitada, a multidisciplinaridade representa um avanço no tratamento de um dado problema de investigação complexo, que pressupõe a interlocução de várias teorias, embora aquém da interdisciplinaridade. A multidisciplinaridade não implica o processo de diálogo, da forma em que está intrínseco à noção da interdisciplinaridade. $\mathrm{O}$ mesmo ocorre com o termo pluridisciplinaridade, pois se trata da "justaposição de disciplinas diversas, situando-se normalmente no mesmo nível hierárquico e agrupadas de maneira a destacar as relações existentes entre elas" (JANTSCH, 1973, p.108).

Com Klein, nos anos 1990, a interdisciplinaridade deixa de ser apenas uma troca, ou interação, e passa a ser um processo para a realização de uma síntese integradora entre saberes de duas ou mais disciplinas. Ela enfatiza que a interdisciplinaridade não é uma temática, nem um conteúdo, mas, sobretudo, um diálogo metodológico em busca de uma síntese.

É um processo para realizar uma síntese integradora, um processo que normalmente começa com um problema, uma questão, um tópico ou um tema. Indivíduos devem trabalhar para superar problemas criados pelas diferenças entre as linguagens e as visões de mundo disciplinares (KLEIN, 1990, p. 188).

Não apenas Klein e Piaget concebem a interdisciplinaridade com aspectos comuns e outros distintos, como também outros estudiosos, a exemplo de Repko que em seu famoso livro entende os estudos interdisciplinares como:

processos desenvolvidos para responder a uma questão, resolver um problema ou abordar um tema que é muito amplo ou complexo para ser tratado adequadamente por uma única disciplina e baseiam-se nas perspectivas disciplinares e integram seus insights para produzir uma compreensão mais abrangente ou um avanço cognitivo. (REPKO, 2008, p. 12).

Nesse mesmo sentido, Costa e Nascimento (2012) consideram a interdisciplinaridade um procedimento de união dialógica das contribuições disciplinares necessárias para análise e compreensão de um objeto complexo. Verifica-se que, na visão dos referidos autores, o termo união dialógica, provinda de Morin, é aqui essencial para diferenciar da pluridisciplinaridade e da multidisciplinaridade. A interdisciplinaridade, chama atenção Nascimento e Pena- 
Veiga (2012), não rompe com as disciplinas. Ela as coloca em contato, configurando novas maneiras de perguntar e de fornecer respostas para os desafios complexos. De distintas maneiras e com variadas intensidades, a interdisciplinaridade aproxima diferentes disciplinas, ao inverso da transdiciplinaridade que tem a pretensão de ir além das disciplinas, transmutandoas.

Os pesquisadores interdisciplinares têm concordado, segundo Repko (2008), que a pesquisa interdisciplinar é um processo e não um método, com uma maior flexibilidade metodológica. Já a transdisciplinaridade pode ser definida como "um processo de aplicação de teorias, conceitos ou métodos através das disciplinas, com o interesse de desenvolver uma síntese abrangente" (REPKO, 2008 , p. 15). Processo, portanto, que aponta para a fusão e desaparecimento das disciplinas.

A CAPES trabalha com o conceito de interdisciplinaridade na vertente do duplo diálogo das disciplinas com o objeto e entre si:

a convergência de duas ou mais áreas do conhecimento, não pertencentes à mesma classe, que contribua para o avanço das fronteiras da ciência e tecnologia, transfira métodos de uma para outra, gerando novos conhecimentos ou disciplinas, e faça surgir um novo profissional com um perfil distinto dos existentes, com formação básica sólida e integradora". (BRASIL/CAPES, 2013 p.12).

Assim, existe um quase consenso de que o principal resultado das práticas interdisciplinares é o processo de integração dos conhecimentos ou das metodologias de duas ou mais disciplinas para produzir uma compreensão mais abrangente de um problema que não pode ser respondido por uma só disciplina, produzindo novos conhecimentos.

\section{As contribuições precursoras sobre a interdisciplinaridade no Brasil}

A expansão da interdisciplinaridade como prática de pesquisa e ensino ganhou maior visibilidade na medida em que os conhecimentos disciplinares criaram insatisfações entre os cientistas, porque pareciam insuficientes para enfrentar os novos fenômenos da sociedade contemporânea. Foi na década de 1960 que as primeiras reflexões sobre interdisciplinaridade empreendidas por Georges Gusdorf ganharam expressão no mundo. Esse autor passou a ser considerado referência na discussão da interdisciplinaridade pela força heurística do seu discurso acerca do lugar que o homem deve ocupar na ciência. Gusdorf propôs integrar o conhecimento e humanizar a ciência. Por isso, definiu como princípio básico, ponto de partida e de chegada do conhecimento científico o homem, por entender que a fragmentação do conhecimento desnaturaliza a natureza e desumaniza a humanidade. O epistemólogo francês considera que é "indispensável que a interdisciplinaridade esteja fundada sobre a competência de cada especialista" (GUSDORF, 1984, p. 30) e que cada especialista reconheça o caráter parcial e relativo de sua disciplina, e de seu ponto de vista. Em particular, quando está voltado para pesquisas de problemas que, para serem tratados, requerem o saber de várias disciplinas. Para isso, os especialistas devem buscar adquirir conhecimento das outras disciplinas, e integrar esses saberes. Assim, sua 
perspectiva da interdisciplinaridade aponta para as mesmas interpretações de Klein e Repko, nas décadas de 1990 e 2000.

O pensamento de Gusdorf pode ser também considerado fundador para as reflexões interdisciplinares no Brasil, pois foi professor e orientador daquele que introduziu tais reflexões em nosso país: o filósofo Hilton Japiassu, com a tese de doutorado intitulada L'épistémologie des relations interdisciplinaires dans les sciences humaines (1975). Japiassu, que publicou diversas obras sobre essa temática no Brasil, é um dos autores mais citados sobre o tema, cujos livros de referência são Interdisciplinaridade e patologia do saber (1976) e O sonho transdisciplinar (2006). No primeiro, inspirado nas obras de Gusdorf, aponta a interdisciplinaridade como uma alternativa para a fragmentação do conhecimento, e se apoia nas definições de interdisciplinaridade propostas no Seminário sobre a "Pluridisciplinaridade e a Interdisciplinaridade" realizado em Nice, em 1970. Como observa em seu livro mais recente, muitos passam a ter consciência de que: "no domínio das ciências humanas e do meio ambiente, por exemplo, os objetos de pesquisa revelam-se tão complexos que só podem ser tratados e solucionados por uma abordagem multi-, inter-ou transdisciplinar" (JAPIASSU, 2006, p. 26). É cada vez mais necessário o encontro entre as disciplinas, uma interação entre os saberes.

Japiassu defende a instauração de um novo espírito científico, no qual "os especialistas deixem de apegar-se às suas verdades congeladas, a seus dogmas estabelecidos e não resistam às novas teorias exteriores a seus domínios de competência" (ibid., p. 27). Apoiado em Gusdorf e Morin, o referido autor entende que a interdisciplinaridade nasce de uma atitude, pois requer um trabalho perseverante e de sínteses sucessivas, para o qual não basta o simples contato e a colaboração entre pesquisadores, pois a "interdisciplinaridade não é uma simples categoria de conhecimento, mas uma categoria de ação, que se apoia no desenvolvimento das próprias disciplinas" (JAPIASSU, 2006, p. 27). Assim, concorda Japiassu com as definições de Klein e de Repko, que veem a interdisciplinaridade como um processo com sujeitos em troca intersubjetiva prolongada.

Outra pesquisadora que introduziu as reflexões interdisciplinares no Brasil foi a filósofa da educação e antropóloga Ivani Catarina Fazenda. Enquanto Japiassu enfatizou a dimensão epistemológica, Fazenda ressaltou a pedagógica, inspirada em Gusdorf, Paulo Freire e no próprio Japiassu (FAZENDA, 1999, 2003 e 2008). A ênfase dos seus trabalhos é a interação entre subjetividades, com destaque maior para as atitudes do que para os métodos:

a primeira das evidências, constatadas após múltiplas observações, descrições e análises de projetos Interdisciplinares em ação, é de que a premissa que mais fundamentalmente predomina é a do respeito do modo de ser de cada um, ao caminho que cada um empreende em busca de sua própria autonomia. Portanto, concluímos que a interdisciplinaridade decorre mais do encontro entre indivíduos do que entre disciplinas [...] (FAZENDA, 2003, p.71). 
Afinal, diz Fazenda, "as disciplinas dialogam quando as pessoas se dispóem $a$ isto" (FAZENDA, 2003, p. 50). Com essa postura, Fazenda enuncia várias atitudes associadas a esse tipo de perspectiva interdisciplinar (cf. ibid., p. 75): abertura para outros modos de conhecimento; reciprocidade que impele à troca e ao diálogo (com pares idênticos, anônimos ou consigo mesmo); humildade ante a limitação do próprio saber; perplexidade ante a possibilidade de desvendar novos saberes; desafio ante o novo e em redimensionar o velho; envolvimento e comprometimento com os projetos e as pessoas neles envolvidas; construção sempre da melhor forma possível; responsabilidade; e destaca, de maneira especial, a alegria e o encontro.

\section{A evolução histórica da interdisciplinaridade no Brasil e o papel precursor da CAPES}

A interdisciplinaridade está sendo implementada no Brasil ao longo dos últimos 40 anos. É possível registrar quatro períodos, de temporalidades distintas, que marcaram este processo. O primeiro (décadas de 1970 a 1990), pode ser caracterizado como fase da implementação por meio de cursos isolados de pósgraduação em algumas universidades. O segundo período (1999 a 2007) foi de crescimento, reconhecimento e institucionalização das práticas e experiências interdisciplinares, já com o apoio do Comitê Multidisciplinar da CAPES, criada em 1999. O terceiro (2008 a 2011) pode ser caracterizado como a fase de consolidação de Programas de Pós-Graduação em diversas universidades, com forte patrocínio do Comitê Interdisciplinar e, mais recentemente, do de Ciências Ambientais da CAPES. $E$, o último período, ora em curso, em que interdisciplinaridade chega à graduação.

Como já citado, foi na década de 1970 que ganharam visibilidade no mundo as discussões sobre a interdisciplinaridade, com os seminários promovidos pela UNESCO e pela OCDE. No caso brasileiro, as discussões ocorreram mais tarde por meio da criação de Programas de Pós-Graduação Interdisciplinares. Como reconhecimento dessa expansão, em 1999, a CAPES criou um Comitê de Avaliação para a Área Multidisciplinar. Com isso, a instituição reconhecia e favorecia o surgimento de novos programas interdisciplinares. Verificou-se, então, um crescimento vertiginoso, em especial na área ambiental.

Bevilacqua (2011) relata que no início da década de 1990, como Secretário Executivo do Ministério de Ciência e Tecnologia - MCT e cofundador do Instituto Interamericano de Pesquisa em Mudanças Globais - IAI, verificou o avanço crescente do número de investigações, cujos temas exigiam o cruzamento de conhecimentos de várias disciplinas, especialmente em tópicos relativos às questões ambientais. Assim, por ele ter acompanhado projetos ricos em aspectos multidisciplinares e interdisciplinares, concluiu que, em determinados temas como os ambientais, o avanço depende da cooperação entre pesquisadores de disciplinas distintas. Em sua área de origem, a engenharia de materiais, a interação ocorria entre disciplinas próximas: física e engenharia, enquanto nas temáticas como as ambientais a cooperação dava-se entre áreas muito mais distantes (geologia, geografia, biologia, sociologia, economia entre outras). As pesquisas conduzidas no âmbito do IAI advinham de grupos de pesquisadores cooperativos e as propostas interdisciplinares emergiam naturalmente, por características dos temas. 
Ainda em 1998, Bevilacqua foi convidado para coordenar o Comitê de implantação da pós-graduação do Laboratório Nacional de Computação Científica - LNCC, onde teve a primeira oportunidade para criar um curso com características claramente interdisciplinares, no qual colaboravam as áreas de mecânica computacional, computação científica e matemática aplicada, com especialistas de outras áreas, destacando-se as ciências biológicas e ambientais, em uma parceria estabelecida entre o Instituto de Biofísica da UFRJ, o Instituto Nacional de Pesquisas da Amazônia - INPA, o Instituto Nacional de Pesquisas Espaciais - INPE e o Museu Paraense Emilio Goeldi. O curso foi encaminhado à CAPES, no fim da década de 1990, e aparentemente influenciou a criação do Comitê Multidisciplinar, pois o presidente e o diretor da avaliação da CAPES convidaram Bevilacqua para coordenar a implementação do novo Comitê. Naquele momento, a CAPES já havia recebido cerca de trinta propostas de Programas de PósGraduação, que foram consideradas multidisciplinares pelos Comitês existentes, os quais, por isso, não as acolheram. Isso obrigava a CAPES a enviá-las a Comitês ad hoc, o que causava problemas pela diversidade dos critérios utilizados por cada um desses Comitês.

Vale registrar também, segundo Bevilacqua (cf. ibid., p. 787-788), que outro momento importante do processo histórico que antecedeu a criação da Área Multidisciplinar da CAPES foi o Manifesto de Angra, resultante de uma reunião promovida pela Coordenação de Programas de Estudos Avançados - COPEA da Universidade Federal do Rio de Janeiro (UFRJ) em 1998, da qual participaram professores, pesquisadores e diretores de agências de fomento à pesquisa. Os dois vetores que apareceram com maior ênfase na reunião, e naquele documento, para que o ensino superior pudesse fazer face ao avanço científico cada vez mais acelerado foram: 1) uma formação acadêmica mais forte e mais ampla, e 2) uma presença maior da interdisciplinaridade na formação em nível superior. Constituiuse, então, um pequeno grupo de professores na UFRJ (Carlos Alberto Aragão de Carvalho Filho, Antônio Paes de Carvalho, Darcy Fontoura de Almeida, Fernando Souza Barros, Herch Moysés Nussenzveig, Leopoldo de Meis, Luiz Davidovich, Luiz Pinguelli Rosa e Ricardo Gattass) com a finalidade de implementar essas propostas. Encontraram, porém, resistências por parte dos órgãos decisórios da Universidade.

Nesse cenário, Bevilacqua teve que, num curto prazo, instituir um Comitê multidisciplinar permanente para analisar as propostas multidisciplinares e estabelecer critérios de análise (cf. BEVILACQUA, 2011, p. 789). Os membros desse Comitê perceberam que, naquele momento, não era possível estabelecer critérios muito rígidos para avaliar as propostas multidisciplinares e interdisciplinares que lhes chegavam, pois elas provinham de áreas muito distintas, com critérios e parâmetros muito diferentes. Concluíam, no entanto, que "promover a convergência de disciplinas, formando grupos multi $e$ interdisciplinares, era uma característica preciosa, cientificamente válida e digna de ser estimulada no Brasil" (BEVILACQUA, 2011, p. 791).

As primeiras normas que o Comitê da Área Multidisciplinar estabeleceu para proceder às avaliações das propostas foram: os pesquisadores deveriam ser produtivos em suas áreas de especialidade; os coordenadores deveriam ser cientistas experientes e com boa produtividade; as propostas deveriam demonstrar a convergência de disciplinas e não apenas visões isoladas do mesmo objeto (multidisciplinaridade); suas publicações deveriam ter coautores de áreas 
diversas e o currículo dos programas deveriam apresentar um horizonte disciplinar amplo ${ }^{1}$.

Os membros iniciais do Comitê foram escolhidos, na medida do possível, dentre todas as áreas do conhecimento acadêmico. Desde o início, os temas ligados às questões ambientais foram os mais numerosos, seguidos daqueles das áreas da biologia, dos ecossistemas e da agricultura. Bevilacqua, em seu artigo, afirma que:

[...] os temas chamados interdisciplinares vieram para ficar. É o processo de evolução do conhecimento que sempre aconteceu ao longo da história. [...] Essa mudança acelerada de paradigma encontra forte resistência na academia, causando às vezes choques de opinião que têm prejudicado o progresso científico (BEVILACQUA, 2011, p. 793).

Ainda observa que a "interdisciplinaridade caminha para a chamada transdisciplinaridade, o que no fundo significa uma nova agregação temática" (ibid., p. 798) e diante dessa nova realidade "a atual separação clássica da universidade em centros e departamentos está obsoleta" (BEVILACQUA, 2011, p. 800).

Em 2008, a CAPES progrediu no sentido de transformar o Comitê Multidisciplinar em Interdisciplinar. O Documento de Área Interdisciplinar, elaborado para o triênio 2010 - 2012, reconhece que a criação dessa nova área na instituição ocorreu em função da "necessidade de se dar conta de novos problemas, de diferentes naturezas e com níveis de complexidade crescente... muitas vezes decorrentes do próprio avanço dos conhecimentos científicos $e$ tecnológicos" (BRASL-CAPES, 2013, p. 11). O documento da CAPES é profundamente inovador, pois admite o diálogo inclusive com "saberes não disciplinares":

A natureza complexa de tais problemas pede diálogos não só entre disciplinas próximas, dentro de uma mesma área do conhecimento, mas entre disciplinas de áreas diferentes, bem como entre saberes disciplinares e saberes não disciplinares da sociedade e das culturas... (BRASIL- CAPES, 2013, p. 11).

E admitia que a interdisciplinaridade provocaria mudanças na estrutura universitária

[...] tendo em vista que um dos maiores desafios deste século é o da (re)ligação de saberes, abre-se na área interdisciplinar um espaço de inovação da organização do ensino da pós-graduação e da pesquisa no Brasil, espaço esse que induz a formação interdisciplinar e humanista dos alunos, docentes e pesquisadores (BRASIL-CAPES, 2013, p. 12).

Desde a sua criação, a Área Multidisciplinar da CAPES tinha a perspectiva de transformar-se em área interdisciplinar. Assim, a mudança de nome, em 2008, foi uma consequência coerente com a intenção original. $O$ que surpreende nesse processo é a velocidade da aceitação e o seu crescimento.

1 O Documento de Área divulgado em 2013 contém orientações e limites explícitos para formatação de propostas com perfil interdisciplinar ou multidisciplinar nas demais áreas de avaliação. De acordo com a Portaria 193/2011, cabe à Diretoria de Avaliação estabelecer o enquadramento final de cada proposta em uma das áreas de avaliação. 


\section{0 crescimento vertiginoso dos cursos de pós-graduação Interdisciplinares}

De acordo com do os dados oficiais da CAPES, a Área Interdisciplinar já era, em 2012, a área com o maior número de cursos de pós-graduação reconhecidos, e apresentava a maior taxa de crescimento. Para organizar melhor suas atividades, foram criadas, em 2006, quatro câmaras temáticas: Meio Ambiente \& Agrárias; Sociais \& Humanidades; Engenharia, Tecnologia \& Gestão; Saúde \& Biológicas. Recentemente, fez-se necessário o desmembramento da Câmara I para a constituição de uma nova área específica (Ciências Ambientais CiAmb). Em 2013, a Área Interdisciplinar foi novamente reestruturada, ficando com a seguinte composição: Desenvolvimento e Políticas Públicas; Sociais \& Humanidades; Engenharia, Tecnologia \& Gestão; Saúde \& Biológicas². Veja-se na figura 01 a distribuição percentual dos cursos por câmara temática da CAPES.

Figura 1. Distribuição percentual dos cursos da área interdisciplinar por câmara temática na CAPES

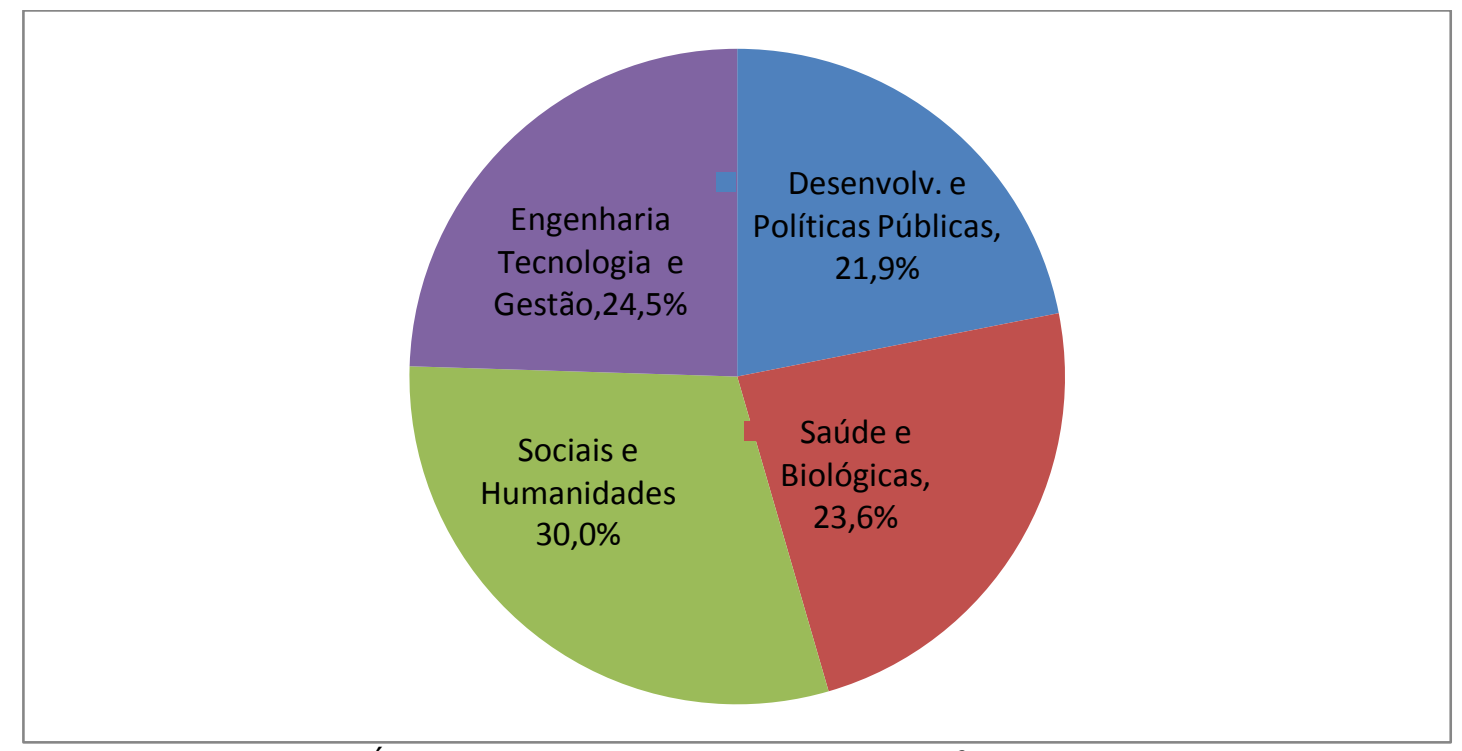

Fonte: Documento da Área Interdisciplinar (CAPES, 2013, p.7)³.

As informações dispostas no gráfico 01 evidenciam o crescimento vertiginoso dos cursos de pós-gradução na Área Interdisciplinar nos últimos 14 anos, que passaram de 46 cursos, em 1999, para 297, em 2012. Observa-se, também, que, apenas por razões de organização interna da gestão administrativa da CAPES, a partir de 2009 não foram incluídos os cursos classificados no outro Comitê, também interdisciplinar, de Ciências Ambientais. Vale destacar que, de acordo com o referido Documento da Área Interdisciplinar da CAPES, a relativa

\footnotetext{
2 A área Interdisciplinar instituiu, desde 2004, as reuniões de acompanhamento com os coordenadores dos programas de pós-graduação (ReCoPI). Essas reuniões produzem relatórios detalhados das discussões com propostas de aprimoramento dos critérios de avaliação, problemáticas teóricas, metodológicas e institucionais. Há, também, alguns intercâmbios frutíferos, como no caso das discussões dos Mestrados Profissionais. Destaca-se que as Câmaras têm incorporado muitas sugestões provenientes das discussões nas ReCoPIs.
} 
redução dos cursos em 2009 e 2010 deveu-se justamente à migração de 47 cursos para a Área de Ciências Ambientais, bem como à desativação de 20 cursos durante o triênio.

Gráfico 1. Número total dos cursos de pós-gradução interdisciplinares na CAPES no período de 1999 a 2013

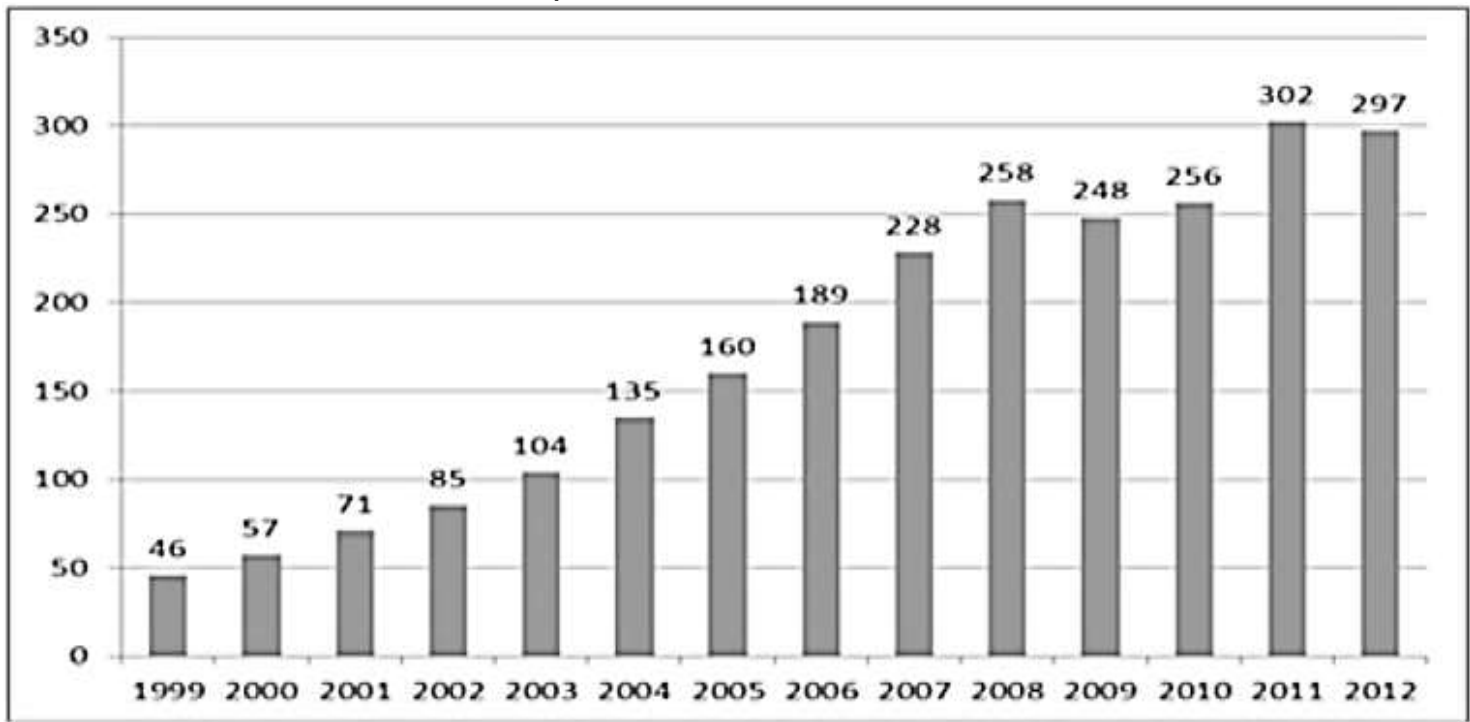

Fonte: Documento da área interdisciplinar da CAPES $(2013$, p.5) .

Por sua vez, conforme o gráfico 2, o crescimento médio anual do número de cursos interdisciplinares entre 2003 a 2012 foi de 34 cursos por ano, atingindo um pico de 64 cursos novos em 2010 e 62 em 2011. Esse foi o momento do ápice de seu crescimento.

Gráfico 2. Evolução anual do número de cursos de pós-graduação interdisciplinares na CAPES no período de 2003 a 2012

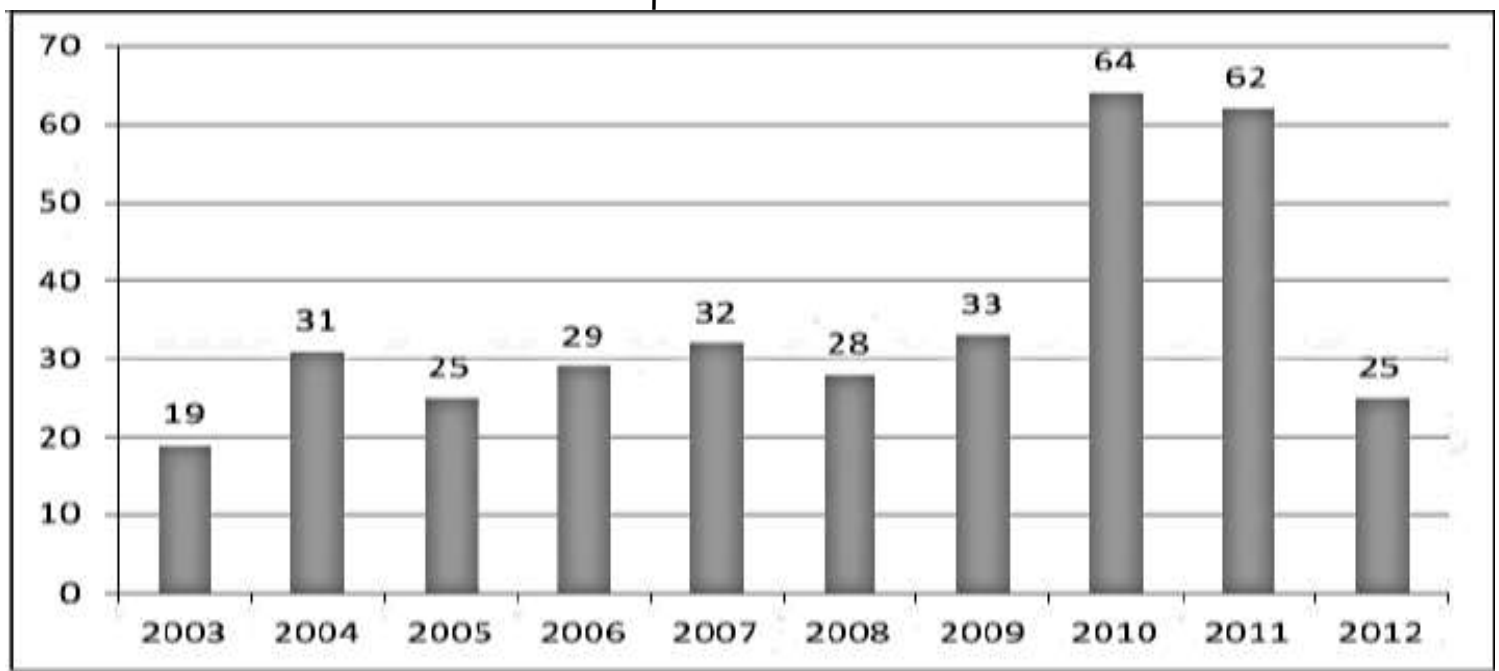

Fonte: Documento da Área interdisciplinar da CAPES (2013, p.6).

${ }^{4}$ O Documento de Área divulgado em 2013 contém orientações e limites explícitos para formatação de propostas com perfil interdisciplinar ou multidisciplinar nas demais áreas de avaliação. De acordo com a Portaria 193/2011, cabe à Diretoria de Avaliação estabelecer o enquadramento final de cada proposta em uma das áreas de avaliação. 
Na tabela 1, são mostrados os casos específicos dos cursos de doutorado multidisciplinares. Verifica-se que havia apenas 10 programas de doutorado na grande área do conhecimento multidisciplinar (1,28\% do total), em 1998, e esse número saltou para 83 programas $(6,29 \%$ do total), em 2008 . Essa pode ser considerada uma mudança estrutural na formação de recursos humanos, em nível de doutorado, ocorrida recentemente no Brasil.

Tabela 1. Número de programas de doutorado por grande área do conhecimento, Brasil, 1998-2008

\begin{tabular}{lrr|r|r|r|r|r|r|r|r|r|r}
\hline Grande área & 1998 & 1999 & 2000 & 2001 & 2002 & 2003 & 2004 & 2005 & 2006 & 2007 & 2008 \\
\hline Total & 782 & 789 & 802 & 912 & 923 & 942 & 1.058 & 1.097 & 1.185 & 1.245 & 1.320 \\
\hline Ciências agrárias & 82 & 86 & 88 & 111 & 110 & 112 & 131 & 137 & 147 & 155 & 165 \\
Ciências biológicas & 99 & 99 & 99 & 113 & 116 & 120 & 138 & 143 & 152 & 145 & 150 \\
Ciências da saúde & 203 & 201 & 207 & 206 & 211 & 221 & 229 & 242 & 257 & 257 & 271 \\
Ciências exatas e da terra & 103 & 105 & 106 & 117 & 116 & 117 & 125 & 129 & 134 & 143 & 150 \\
Ciências humanas & 105 & 104 & 104 & 131 & 131 & 134 & 144 & 146 & 163 & 173 & 186 \\
Ciências sociais aplicadas & 50 & 50 & 51 & 64 & 64 & 64 & 84 & 86 & 94 & 103 & 109 \\
Engenharias & 79 & 81 & 81 & 91 & 93 & 94 & 114 & 117 & 127 & 130 & 133 \\
Linguística, letras e artes & 51 & 51 & 51 & 58 & 58 & 58 & 60 & 61 & 68 & 70 & 73 \\
Multidisciplinar & 10 & 12 & 15 & 21 & 24 & 22 & 33 & 36 & 43 & 69 & 83 \\
\hline
\end{tabular}

Fonte: CGEE- Centro de Gestão e Estudos Estratégicos, In: Doutores 2010: estudos da demografia da base técnico-científica (p.109).

O crescimento dos cursos de doutorado no Brasil entre 1998 e 2008 não foi igualmente distribuído entre as grandes áreas do conhecimento. O fato mais marcante foi a rápida expansão de programas de doutorado interdisciplinar, que cresceram mais de $730 \%$ entre 1998 e 2008, distribuídos, principalmente, nas áreas do meio ambiente, biotecnologia, materiais, ciências sociais e humanidades. Essa característica está certamente associada à crescente evolução da ciência que tem integrado áreas tradicionais do conhecimento científico, aumentando a densidade de conhecimento científico na fronteira do desenvolvimento tecnológico e ampliando as zonas de fertilização mútua. 
Tabela 2. Taxa de crescimento percentual do número de programas de doutorado por grande área do conhecimento, Brasil, 1998-2008

\begin{tabular}{l|r|r|r|r|r|r|r|r|r|r|r|r}
\hline Grande área & 1998 & 1999 & 2000 & 2001 & 2002 & 2003 & 2004 & 2005 & 2006 & 2007 & 2008 & $\begin{array}{c}1998 \mathrm{a} \\
\mathbf{2 0 0 8}\end{array}$ \\
\hline Total &.. & 0,9 & 1,6 & 13,7 & 1,2 & 2,1 & 12,3 & 3,7 & 8,0 & 5,1 & 6,0 & 68,8 \\
\hline Ciências agrárias &.. & 4,9 & 2,3 & 26,1 & $-0,9$ & 1,8 & 17,0 & 4,6 & 7,3 & 5,4 & 6,5 & 101,2 \\
Ciências biológicas &.. & 0,0 & 0,0 & 14,1 & 2,7 & 3,4 & 15,0 & 3,6 & 6,3 & $-4,6$ & 3,4 & 51,5 \\
Ciências da saúde &.. & $-1,0$ & 3,0 & $-0,5$ & 2,4 & 4,7 & 3,6 & 5,7 & 6,2 & 0,0 & 5,4 & 33,5 \\
Ciências exatas e da & & & & & & & & & & & & \\
terra &.. & 1,9 & 1,0 & 10,4 & $-0,9$ & 0,9 & 6,8 & 3,2 & 3,9 & 6,7 & 4,9 & 45,6 \\
Ciências humanas &.. & $-1,0$ & 0,0 & 26,0 & 0,0 & 2,3 & 7,5 & 1,4 & 11,6 & 6,1 & 7,5 & 77,1 \\
Ciências sociais & & & & & & & & & & & & \\
aplicadas &.. & 0,0 & 2,0 & 25,5 & 0,0 & 0,0 & 31,3 & 2,4 & 9,3 & 9,6 & 5,8 & 118,0 \\
Engenharias &.. & 2,5 & 0,0 & 12,3 & 2,2 & 1,1 & 21,3 & 2,6 & 8,5 & 2,4 & 2,3 & 68,4 \\
Linguística, letras e artes &.. & 0,0 & 0,0 & 13,7 & 0,0 & 0,0 & 3,4 & 1,7 & 11,5 & 2,9 & 4,3 & 43,1 \\
Multidisciplinar &.. & 20,0 & 25,0 & 40,0 & 14,3 & $-8,3$ & 50,0 & 9,1 & 19,4 & 60,5 & 20,3 & 730,0 \\
\hline
\end{tabular}

Fonte: CGEE- Centro de Gestão e Estudos Estratégicos, In: Doutores 2010: estudos da demografia da base técnico-científica (p.110).

Correspondente ao crescimento dos cursos de doutorado observa-se o aumento do número de doutores, conforme a tabela 03. Desde 1996, quando foram formados os primeiros doutores provenientes dos cursos multidisciplinares, passou-se de 3 doutores para 415 em 2008.

Tabela 3. Número de doutores titulados no Brasil por grande área do conhecimento, 1996-2008

\begin{tabular}{|c|c|c|c|c|c|c|c|c|c|c|c|c|c|c|}
\hline Grande área & 1996 & 1997 & 1998 & 1999 & 2000 & 2001 & 2002 & 2003 & 2004 & 2005 & 2006 & 2007 & 2008 & $\begin{array}{r}1996 \text { a } \\
2008\end{array}$ \\
\hline Total & 2.830 & 3.472 & 3.797 & 4.713 & 5.197 & 5.753 & 6.567 & 7.690 & 8.080 & 8.982 & 9.364 & 9.913 & 10.705 & 87.063 \\
\hline $\begin{array}{l}\text { Ciências } \\
\text { agrárias } \\
\text { Ciências }\end{array}$ & 01 & 54 & 439 & 479 & 545 & 664 & 758 & 1.005 & 972 & 1.121 & 1.160 & 1.217 & 1.315 & 10.340 \\
\hline $\begin{array}{l}\text { biológicas } \\
\text { Ciências da }\end{array}$ & 391 & 467 & 504 & 591 & 658 & 731 & 832 & 964 & 1.039 & 1.140 & 1.157 & 1.154 & 1.238 & 10.866 \\
\hline $\begin{array}{l}\text { saúde } \\
\text { Ciências exatas }\end{array}$ & 545 & 654 & 733 & 1.010 & 1.003 & 1.064 & 1.386 & 1.491 & 1.467 & 1.681 & 1.731 & 1.797 & 1.959 & 16.521 \\
\hline $\begin{array}{l}\text { e da terra } \\
\text { Ciências }\end{array}$ & 457 & 516 & 536 & 638 & 707 & 716 & 697 & 871 & 904 & 963 & 951 & 988 & 1.132 & 10.076 \\
\hline $\begin{array}{l}\text { humanas } \\
\text { Ciências sociais }\end{array}$ & 422 & 613 & 639 & 749 & 876 & 1.004 & 1.106 & 1.239 & 1.327 & 1.495 & 1.503 & 1.689 & 1.861 & 14.523 \\
\hline aplicadas & 181 & 184 & 266 & 327 & 425 & 470 & 601 & 678 & 751 & 813 & 890 & 809 & 868 & 7.263 \\
\hline $\begin{array}{l}\text { Engenharias } \\
\text { Linguística, }\end{array}$ & 389 & 463 & 506 & 640 & 678 & 731 & 748 & 926 & 1.041 & 1.110 & 1.123 & 1.169 & 1.221 & 10.745 \\
\hline letras e artes & 141 & 202 & 158 & 235 & 251 & 315 & 367 & 409 & 452 & 496 & 616 & 710 & 696 & 5.048 \\
\hline Multidisciplinar & 3 & 9 & 16 & 44 & 54 & 58 & 72 & 107 & 127 & 163 & 233 & 380 & 415 & 1.681 \\
\hline
\end{tabular}

Fonte: CGEE- Centro de Gestão e Estudos Estratégicos, In: Doutores 2010: estudos da demografia da base técnico-científica (p.139).

A intensidade do crescimento do número de doutores formados na área interdisciplinar pode ser mais bem visualizada no gráfico 3, com a maior taxa percentual de crescimento médio anual com bolsa da CAPES, entre 1996-2008, 
$59,8 \%{ }^{5}$. Vale registrar, também, que em 1996 ainda não existia o Comitê Multidisciplinar.

Gráfico 3. Percentual de crescimento anual médio do número de doutores formados no Brasil, de 1996 a 2008, por grandes áreas do conhecimento

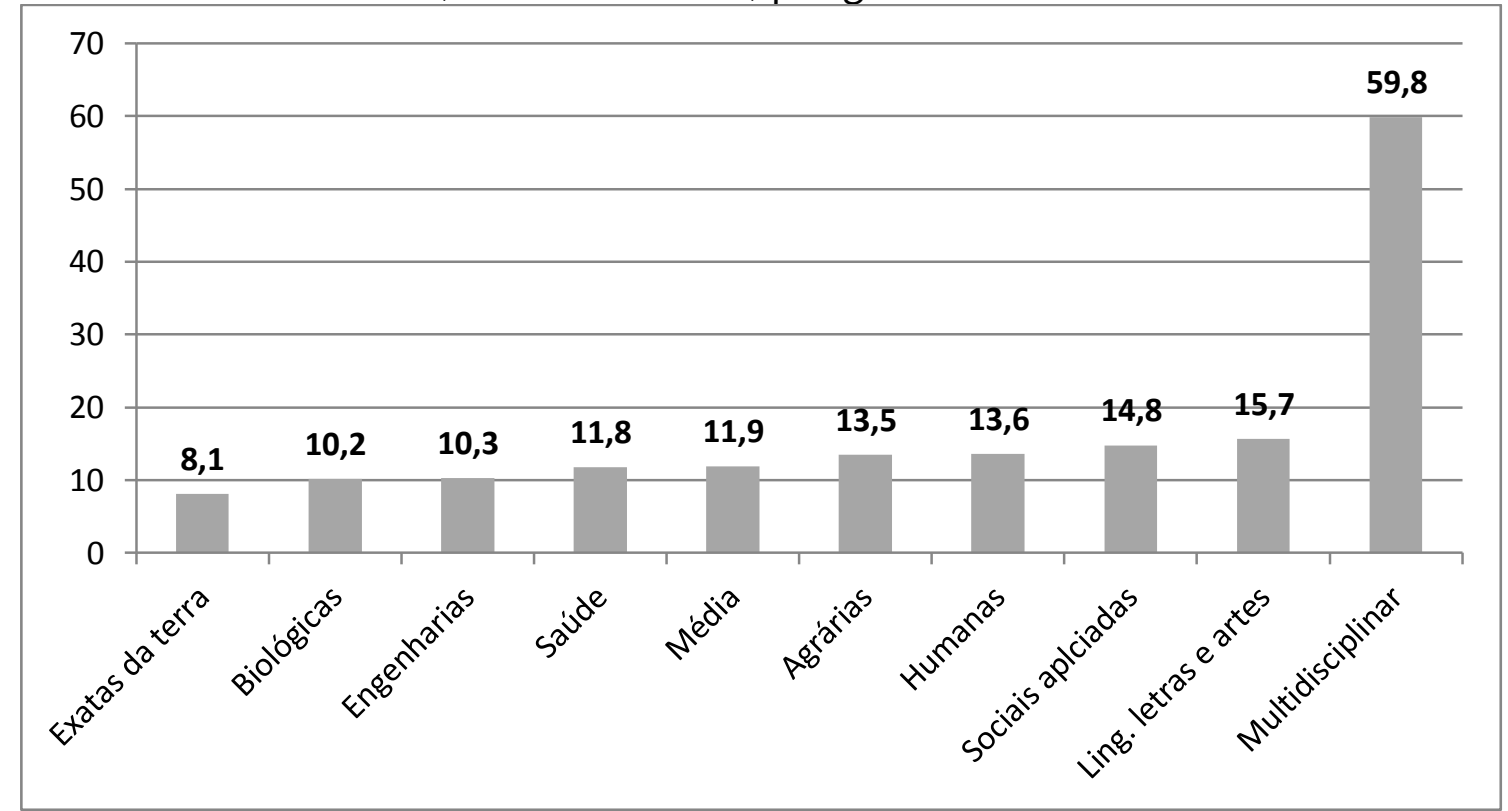

Fonte: Dados do Sistema Coleta CAPES, 2010.

Em relação à evolução dos discentes, segundo a CAPES (2010), houve um crescimento de $191 \%$ dos alunos matriculados nos cursos de pós-graduação da Área Interdisciplinar. Em 2002, o número de alunos totalizava 3.423 e, em 2012, 9.949 alunos. Acompanhando esse movimento, verifica-se, igualmente, um acréscimo na concessão de bolsas de estudo destinadas aos alunos dos cursos de doutorado interdisciplinar, obtendo uma elevada taxa de crescimento de $284 \%$, visto que o número de bolsas saltou de 194, em 2004, para um total de 744, em 2012. Do mesmo modo, houve um aumento no número de concessão de bolsas de estudo de pós-doutorado interdisciplinar, que inicialmente era de apenas 10, em 2004, e cresceu para 81, em 2012. Nesse caso, o aumento foi de $710 \%$. Em relação ao número de bolsas de estudo para os mestrandos de cursos interdiciplinares, a taxa de crescimento foi igualmente elevada, 321\%. Passou-se de 637 bolsas, em 2004, para 2.682, em 2012.

Quanto à avaliação dos cursos da Área Interdisciplinar, observa-se, de maneira geral, uma melhoria significativa da sua qualidade. Conforme gráfico 4, registra-se uma clara evolução, pois em 2007 havia 83 cursos com nota 3 e, em 2010, esse número foi reduzido para 65; os cursos com nota 4 ficaram estáveis, pois passaram de 58 para 57, enquanto os com nota 5 subiram de 16 para 19 cursos. Em 2007, não existia curso com a nota 6, e em 2010 eles eram 5.

\footnotetext{
${ }^{5}$ Nos dados supracitados não estão inclusos dados sobre as bolsas concedidas pelo CNPq.
} 
Gráfico 4. Resultados comparativos das últimas avaliações dos cursos da área interdisciplinar entre o período de 2007 a 2010

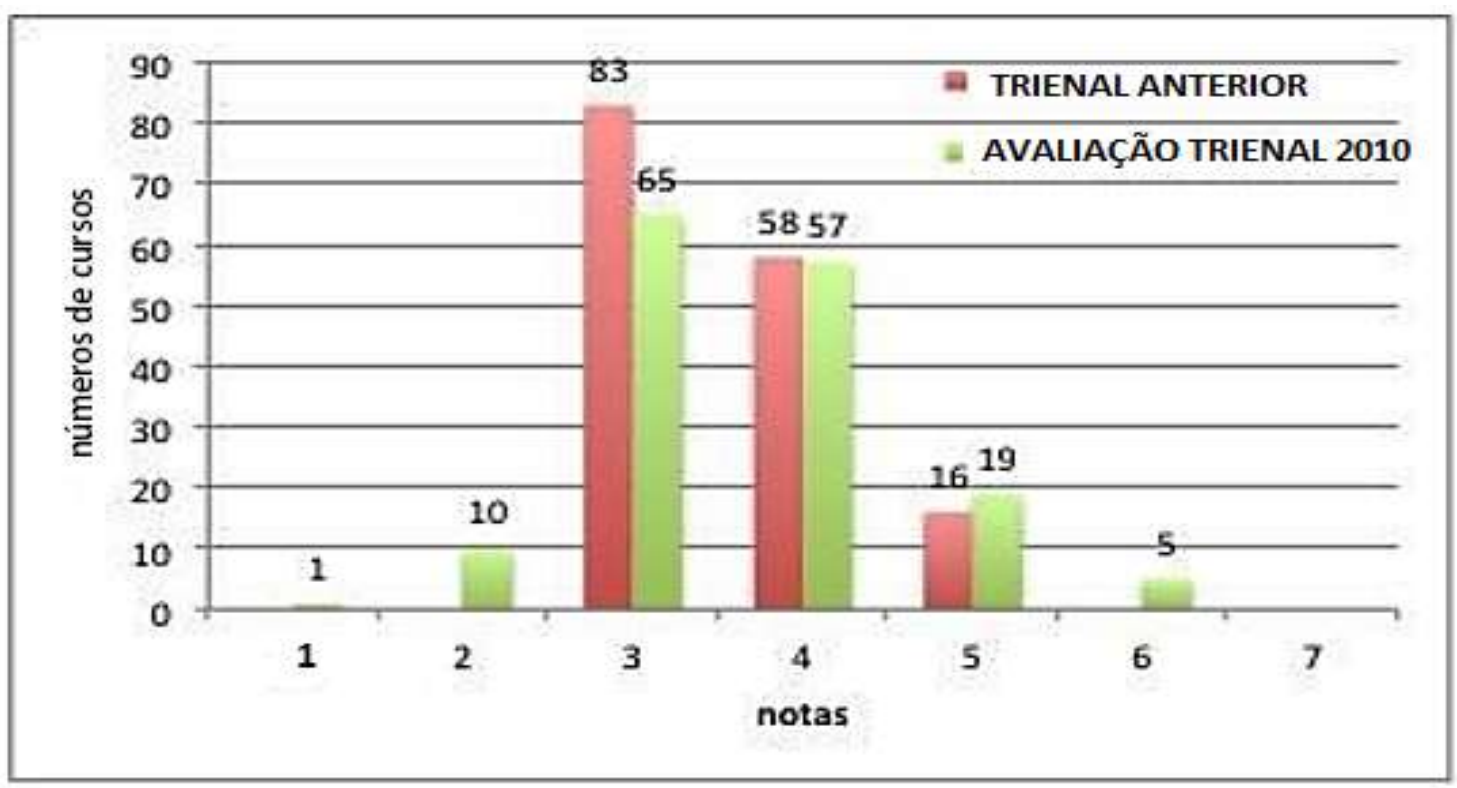

Fonte: Documento de área Interdisciplinar (CAPES, 2013, p.9).

É importante ressaltar que existe um grande desequilíbrio regional da localização e distribuição dos cursos de pós-graduação interdisciplinares no Brasil, como em outras áreas, conforme o mapa 01, e na tabela trienal ao lado da distribuição dos programas por regiões brasileiras. A Região Sudeste abriga 41,2 \% dos cursos interdisciplinares, seguida da Região Nordeste, com 19,4 \%, Região Sul, com 18,3\%, Região Centro Oeste, com 12,8\% e a Região Norte, com apenas $8,3 \%$. Contudo, em todas as regiões brasileiras, observa-se crescimento dos cursos de pós-graduação interdisciplinar. 
Mapa 1. Distribuição Estadual do número de cursos e tabela com a evolução trienal dos Programas de Pós-Graduação na área interdisciplinar por regiões, 2010/2012)

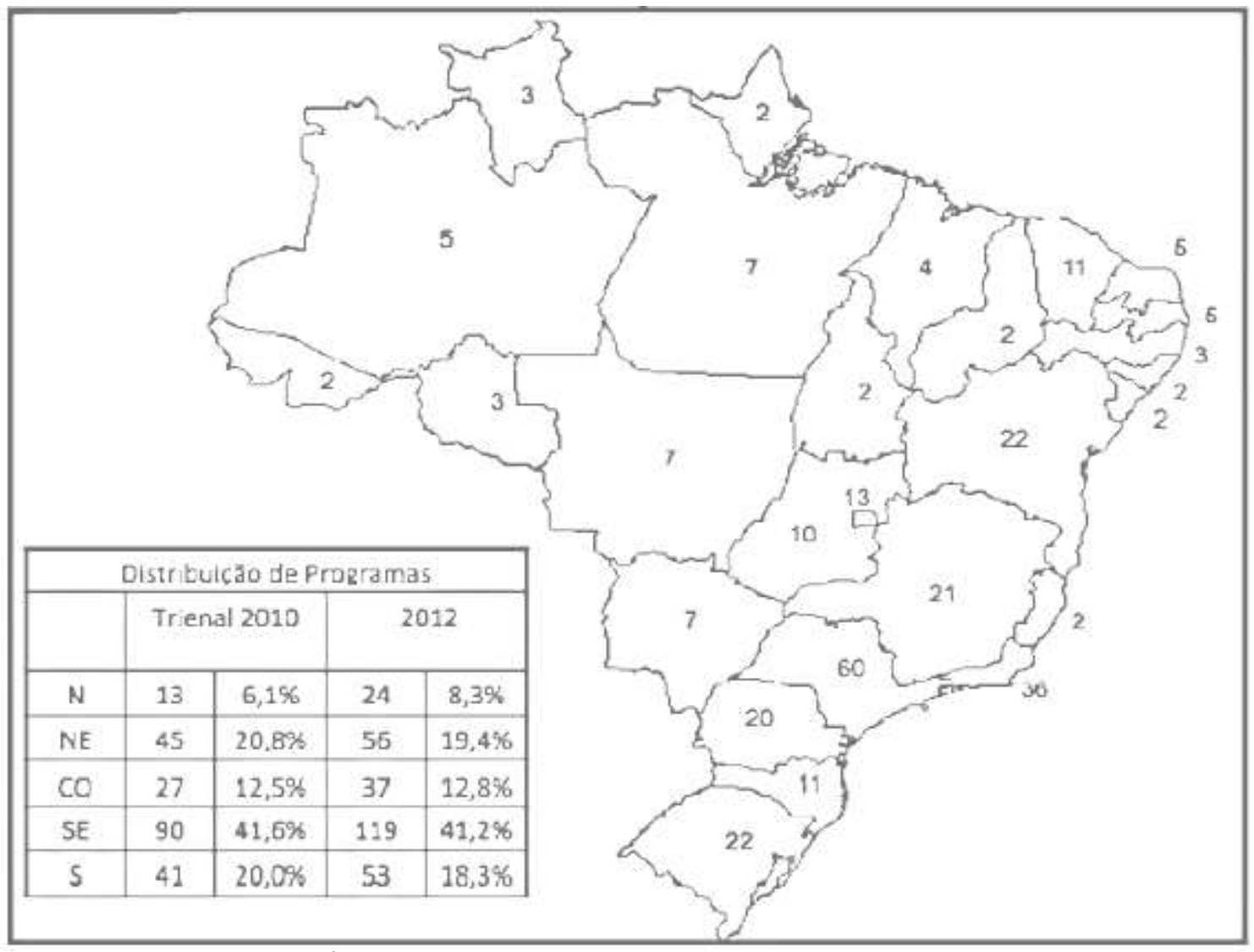

Fonte: Documento de Área Interdisciplinar da CAPES (2013, p.10) ${ }^{6}$.

\section{A interdisciplinaridade nos cursos de graduação no Brasil}

À expansão da interdisciplinaridade na pós-graduação nos anos 1990/2000 sucedeu o seu surgimento e crescimento na graduação. Mais de 20 mil estudantes de universidades federais brasileiras cursam, atualmente, bacharelados interdisciplinares. Apesar de o número ainda responder por aproximadamente $3 \%$ do total de matrículas no segmento, a nova modalidade de graduação tem sido uma das mais procuradas nas últimas edições do Exame Nacional do Ensino Médio - ENEM. Aparentemente é um dos instrumentos indutores do Ministério da Educação para mudar o modelo curricular das Instituição de Educação Superior - IES.

Em 2013, pelo menos 18 universidades federais ofereceram bacharelados interdisciplinares em quatro grandes áreas do conhecimento - humanidades, artes, saúde e ciência e tecnologia. Nesses cursos, o aluno pode realizar sua escolha profissional ao longo da formação, de acordo com a evolução da sua experiência acadêmica. Destaca-se a oferta de diplomas de ensino superior que podem ser utilizados para o ingresso no mundo do trabalho em áreas que não exigem

\footnotetext{
${ }^{6}$ As siglas utilizadas na tabela significam: $\mathrm{N}$ - Norte, S - Sul, CO- Centro Oeste, SE - Sudeste e NE - Nordeste.
} 
formação específica. Oportunizam aos egressos participarem dos concursos públicos que demandam formação universitária. Após o bacharelado, é possível dar sequência aos estudos em cursos de graduação tradicionais, sem a necessidade de novo processo seletivo, como engenharia, economia, medicina e outros, com duração mais reduzida, conforme o desempenho do aluno.

Verifica-se que o Ministério da Educação vem incentivando, por meio do Programa de Apoio ao Plano de Reestruturação e Expansão das Universidades Federais - REUNI, criado pelo Decreto $n^{\circ}$ 6.096/2007, as instituições federais na adoção desse modelo de bacharelados. O seu objetivo principal é o de criar condições para a ampliação do acesso e permanência na educação superior, no nível de graduação presencial, pelo melhor aproveitamento da estrutura física e de recursos humanos das universidades federais.

A expansão da rede federal das universidades foi intensificada desde 2003, com a interiorização dos seus campi ${ }^{7}$. Com isso, o número de municípios atendidos por estas universidades passou de 114, em 2003, para 237, até o final de 2011. Desde o início da expansão, foram criadas 14 novas universidades e mais de 100 novos campi, com a criação de 2.428 novos cursos. O número global de docentes aumentou aproximadamente 44\%, passando de 49,8 mil, em 2003, para 71,2 mil, em 2012. Já o número de matrículas na graduação e pós-graduação nas instituições federais quase dobrou, passando de 596,2 mil para mais de um milhão. Entretanto, os reflexos desse crescimento foi o aparecimento de vários problemas: obras a serem concluídas, falta de equipamentos, atrasos nas licitações e na realização de concursos para docentes e servidores, dentre outros.

De acordo com o Relatório do Ministério da Educação - MEC de avaliação do Programa REUNI, em 2012, há entusiasmo em torno dos bacharelados interdisciplinares. Por ser um processo longo e complexo, exigirá readequações dos projetos institucionais das Instituto Federal do Espirito Santo - IFES, os quais são apontados como uma das maiores dificuldades ao cumprimento das metas pelas universidades que aderiram ao REUNI. Não é uma tarefa fácil a de implantar bacharelados interdisciplinares, já que, para ter sucesso, é preciso ter um adequado Projeto Pedagógico, materiais didáticos de acordo com o conteúdo e o perfil condizente dos professores. Ressalta-se, atualmente, a realização de alguns fóruns de discussão como um instrumento de enfrentamento dos problemas dos cursos de bacharelados interdisciplinares. As universidades e coordenadores dos cursos estão se reunindo, periodicamente, com o objetivo de promover troca de experiências na implantação desses cursos.

Diversas universidades estão promovendo a discussão sobre a interdisciplinaridade na Graduação. No caso da Universidade Federal de Minas Gerais - UFMG, o tema foi discutido em uma série de atividades ao longo de 2012 e 2013, no ciclo de seminários denominado "A Universidade do Futuro". O seu objetivo foi a de discutir a recente experiência dos Bacharelados Interdisciplinares das universidades brasileiras, assim como programas similares em instituições estrangeiras, como os Colleges americanos. A Universidade de Brasilia - UnB,

\footnotetext{
${ }^{7}$ Registra-se que a expansão e a criação de campus das universidades federais no interior do Brasil não são iniciativas novas, visto que diversas instituições federais já vinham implementando as suas políticas voltadas ao processo de interiorização, como nos casos da Universidade Federal do Pará, das Universidades Federais de Minas Gerais, do Rio Grande do Sul, dentre diversas outras.
} 
Universidade de São Paulo - USP, Universidade Estadual de Campinas - Unicamp, Universidade Federal do Rio de Janeiro - UFRJ, Universidade Federal da Bahia UFBA, dentre outras, também realizaram, com participação e apoio dos gestores, vários ciclos de debates nacionais e internacionais sobre a temática da interdisciplinaridade.

Recentemente, 2010, a USP realizou um seminário, no quadro da Escola de Altos Estudos da Capes, sob a coordenação de Arlindo Philippi Jr, sobre a Interdisciplinaridade na Pesquisa e Ensino da Pós-Graduação. O referido evento contribuiu sobremaneira para despertar na comunidade científica brasileira a importância da interdisciplinaridade. Em abril de 2013, a mesma USP realizou outro seminário com a participação de especialistas externos debatendo o tema "Interdisciplinaridade no ensino, na pesquisa e extensão".

Dentro desse contexto, é importante apontar que a CAPES realizou, em 2012, um Seminário Internacional com o tema "Interdisciplinaridade e Transdisciplinaridade no Ensino, Pesquisa, Extensão em Educação, Ambiente e Saúde". Em 2013, foram realizados outros cinco seminários, sendo um em cada uma das regiões brasileiras. O objetivo foi o de aprofundar os debates visando sistematizar propostas, limites e possibilidades da interdisciplinaridade. As propostas foram apresentadas em outro Seminário Internacional, ainda da CAPES, com a participação das universidades e órgãos governamentais em 2014.

A proposta de cursos de graduação interdisciplinar tem sido muito bem aceita e desenvolvida pelas novas universidades criadas nesta década. Dentre elas, destaca-se a Universidade Federal do ABC - UFABC que começou suas atividades em 2006 apenas com os bacharelados interdisciplinares em ciência e tecnologia e, recentemente, ampliou para a área de ciências e humanidades. Eles são a única forma de ingresso dos alunos e podem ser complementados, com matrícula garantida ao final do curso, pela formação mais profissionalizante de dois anos em nove opções de engenharia, oito graduações regulares e cinco licenciaturas. No caso dos cursos oferecidos pela UFABC, o Projeto Acadêmico é dividido em seis grandes eixos temáticos: 1) Estrutura da matéria; 2) Transformações; 3) Energia; 4) Informação e Comunicação; 5) Representação e Simulação; e 6) Humanidades.

A Universidade Federal do Oeste do Pará - UFOPA, criada pela Lei $n^{\circ}$ 12.085, de 5/11/2009, por desmembramento das unidades da Universidade Federal do Pará - UFPA e da Universidade Federal Rural da Amazônia - UFRA, tem o objetivo de ensino, pesquisa e extensão na vasta região da Amazônia. A UFOPA tem por princípio a relevância social traduzida em formar e pesquisar por meio do engajamento social dos discentes. O modelo acadêmico estrutura-se conforme os princípios da inovação, interdisciplinaridade, flexibilidade curricular e formação em ciclos. Dentre os cursos oferecidos, destacam-se os bacharelados interinstitucionais em ciências jurídicas, da sociedade e ciências da educação.

A interdisciplinaridade e flexibilidade na organização curricular foi também uma característica predominante no Projeto do Campus da Universidade Federal Rural do Rio de Janeiro - UFRRJ em Nova Iguaçu, por meio do Instituto Multidisciplinar. Nasceu fruto da política de interiorização do MEC com o objetivo de atender às necessidades e demandas do desenvolvimento socioeconômico e cultural da Baixada Fluminense.

No caso da UFBA, os bacharelados interdisciplinares de humanidades, artes, ciência, tecnologia e saúde foram adicionados em 2009 à imensa lista de 
graduações. Isso pode ser visto na tabela seguinte, em que são mostrados os principais cursos oferecidos nas principais universidades brasileiras. Sabedor que se trata de uma lista incompleta.

Quadro 1. Relação de universidades e áreas dos bacharelados interdisciplinares

\begin{tabular}{|c|c|c|c|}
\hline UFABC & $\begin{array}{l}\text { Bl em Ciências e Tecnologia } \\
\text { Bl em Ciências e Humanidades }\end{array}$ & \multirow[t]{2}{*}{ UFJF } & $\begin{array}{l}\text { Bacharelado em Artes e Design } \\
\text { Bacharelado em Ciências Exatas }\end{array}$ \\
\hline \multirow[b]{2}{*}{ UFBA } & \multirow{2}{*}{$\begin{array}{l}\text { Bl em Artes } \\
\text { Bl em Humanidades } \\
\text { Bl em Ciêncios e Tecnologia } \\
\text { Bl em Saúde }\end{array}$} & & $\begin{array}{l}\text { Bacharelado em Ciências } \\
\text { Humanas }\end{array}$ \\
\hline & & UFSC & $\begin{array}{l}\text { Bacharelado em Ciéncias Rurais } \\
\text { Bacharelado em Tecnologias da } \\
\text { Informação e Comunicação }\end{array}$ \\
\hline UFSJ & $\begin{array}{l}\text { Bl em Ciência e Tecnologia } \\
\text { Bl em Biossistemas }\end{array}$ & UNIFAL & $\begin{array}{l}\text { Bl em Ciência e Economia } \\
\text { Bl em Ciência e Tecnologia }\end{array}$ \\
\hline UFRB & $\begin{array}{l}\text { Bacharelado em Ciências Exatas e } \\
\text { Tecnológicas } \\
\text { Blem Saúde }\end{array}$ & \multirow{2}{*}{ UFOPA } & $\begin{array}{l}\text { Bl em Ciências Juridicas } \\
\text { Bl em Ciências do Sociedade }\end{array}$ \\
\hline UFRN & $\begin{array}{l}\text { Bacharelado em Clëncias e } \\
\text { Tecnologia }\end{array}$ & & Bl em Ciências da Educaçōo \\
\hline UFERSA & $\begin{array}{l}\text { Bacharelado em Cièncias e } \\
\text { Tecnologia }\end{array}$ & UNESP & Bacharelado em Ciências Exatas \\
\hline UFVJM & $\begin{array}{l}\text { Bl em Humanidades } \\
\text { Bl em Ciência e Tecnologia }\end{array}$ & UNICAMP & $\begin{array}{l}\text { Programa de Formaçōo } \\
\text { Interdisciplinar Superior (ProFIS) }\end{array}$ \\
\hline
\end{tabular}

Fonte: relatório de avaliação do REUNI do MEC/SESU, 2012. Informações reagrupadas pelos autores.

Os ciclos desses bacharelados interdisciplinares são quadrimestrais, com duração de três anos. O aluno pode montar e estruturar sua própria grade escolhendo os créditos que deseja cumprir, além das disciplinas obrigatórias do currículo. Na primeira metade do curso, o aluno tem uma formação mais ampla e genérica, com matérias de várias áreas; nos últimos períodos, pode dedicar-se exclusivamente a temas mais específicos da sua área escolhida, de caráter profissionalizante.

A ideia central é que os bacharelados interdisciplinares acompanhem a reorganização do mundo do trabalho e valorizem as competências sociais, antes pouco consideradas nos ambientes acadêmicos. O objetivo é formar um profissional mais dinâmico, de alta qualidade, versátil, com capacidade de enfrentar os problemas da realidade, de forma crítica e criativa.

Assim, a perspectiva de avanços da interdisciplinaridade nos cursos de graduação enfrentará mais dificuldades e limitações que na pós-graduação, uma vez que a cultura acadêmica disciplinar é muito arraigada nesse nível de ensino. $E$ o consenso sobre esse tipo de formação é menor, na medida em que a formação disciplinar ainda é considerada relevante, inclusive pelos cursos de pós-graduação interdisciplinares. De toda forma, é muito cedo para uma avaliação de como reagirão mercado, comunidade universitária, gestores e sociedade, e sobretudo o mercado em relação a esses novos alunos. 


\section{Desafios e possibilidades da interdisciplinaridade}

Em relação à interdisciplinaridade, os desafios são e serão grandes para todas as universidades, programas, cursos e agências.

Dificuldades existem no processo de avaliação de desempenho dos alunos de graduação, visto que os mecanismos do Exame Nacional de Avaliação dos Cursos de Graduação - ENADE não são adaptados para os bacharelados interdisciplinares, e não há parâmetros e processos adequados para a formação dos avaliadores. O atual modelo de avaliação é, ainda, embrionário e baseado em visitas "in loco" às instituições, sem um processo padronizado, visto que as realidades são múltiplas e variadas em cada universidade. Outro desafio é a ausência das diretrizes curriculares aprovado pelo Conselho Nacional de Educação - CONAE.

Entretanto, a emergência da interdisciplinaridade está estimulando a inclusão de novos atores no mundo acadêmico, inclusive temas de pesquisa e objetos de fomento. Universidades que não se destacam por seu orçamento ou prestígio tradicional começam a alcançar reconhecimento internacional porque são mais interdisciplinares e abertas às mudanças na sua forma de produção do conhecimento. Elas podem estar colaborando para um novo projeto de ciência com forte integração de saberes para investigar aquilo que as disciplinas isoladas não registram. Aliás, objeto da tese de doutorado defendida por Sommerman (2012) que, de forma aprofundada, trata das questões da interdisciplinaridade e da transdisciplinaridade como novas formas de conhecimento para a articulação de saberes no contexto da ciência e do conhecimento em geral e, em especial, sua contribuição aos campos da educação, da saúde e do meio ambiente. Outro estudo interessante foi apresentado por Bordas (2007) em relação à Universidade Federal do Rio Grande do Sul - UFRGS. Já no estudo realizado por Nascimento e Pena-Veiga (2012) foram selecionadas três novas dimensões para a avaliação da Universidade Federal do Tocantisn - UFT: inserção social, interdisciplinaridade e sustentabilidade, com recomendações aos dirigentes. Já no aspecto particular da interdisciplinaridade, Costa e Nascimento (2012) realizaram um estudo muito interessante de benchmarking com uma adequada reflexão sobre as possibilidades e os limites da interdisciplinaridade, comparando universidades de diversos países. Além desses, há a obra organizada por Philippi jr. e Silva Neto (2011), um dos livros mais completos sobre a interdisciplinaridade, sob o tema: Interdisciplinaridade em ciência, tecnologia \& inovação, ganhando, inclusive, o prêmio Jabuti pela sua excelente qualidade.

Outros desafios encontram-se na promoção da abertura para o enfrentamento de novas perspectivas teórico-metodológicas de pesquisa, ensino e inovação; diálogos cada vez mais estreitos entre disciplinas de diferentes áreas do conhecimento, assim como destas com as filosofias das ciências; incorporação de metodologias interdisciplinares nos projetos de pesquisa dos docentes e discentes; reconhecimento de que diferentes concepções podem ser adotadas nas pesquisas e no ensino interdisciplinar, valorizando e reconhecendo a diversidade que a área comporta; as avaliações dos diferentes programas da Área Interdisciplinar; identificação de canais para a intensificação do diálogo inter e intracâmaras da Área Interdisciplinar, para as trocas de experiências entre os programas e a divulgação do conhecimento gerado. (CAPES, 2013, p.13). 
Grandes desafios ainda devem ser enfrentados, e superados, em nossas instituições de ensino e pesquisa no Brasil, visando dar continuidade à tarefa de introduzir e fortalecer os estudos interdisciplinares. No entanto, é uma aventura que merece ser observada de perto, pois, com o tempo, e os resultados das diversas experiências em curso, o debate poderá assumir outras dimensões ou abordagens diferentes destas até aqui apresentadas.

O processo de implantação da interdisciplinaridade na pós-graduação foi alicerçado em editais de fomento que incentivaram e despertaram muito interesse na comunidade acadêmica, em especial, em temas considerados estratégicos para o desenvolvimento do Brasil. Projetos foram induzidos para serem desenvolvidos por meio de redes e consórcios de pesquisadores de áreas e instituições distintas, cujos temas requerem aplicação de metodologias e práticas interdisciplinares. Os dirigentes dos institutos nacionais vinculados ao Ministério da Ciência e Tecnologia e à Financiadora de Estudos e Projetos - FINEP, apesar das inúmeras resistências, prometem também valorizar e dar maior importância à interdisciplinaridade.

No caso do CNPq, contudo, as resistências foram e são grandes, visto que a instituição carrega uma longa e bem sucedida trajetória alicerçada no modelo disciplinar. Há, contudo, fortes pressões da comunidade acadêmica para abrir-se ao debate sobre a interdisciplinaridade e adotar políticas indutoras da interdisciplinaridade, seguindo uma tendência já verificada em diversos outros institutos de pesquisas na Europa, nos Estados Unidos e na Ásia.

Pode-se afirmar que está ocorrendo um processo gradativo de evolução da prática da ciência disciplinar para a da interdisciplinaridade? Aparentemente sim, no sentido de um complemento da evolução do pensamento científico disciplinar e não a sua simples substituição. A crítica aos limites do conhecimento disciplinar, bem como a crise da ciência e a falta das explicações adequadas e prudentes para muitos fenômenos atuais estão favorecendo o aparecimento da interdisciplinaridade, conforme vem demonstrando, recentemente, os estudos de: Morin (1999), (2000), (2002); Santos (2000), (2003); Pombo (2006); Klein (1986a), (1986b), (1996) e Fazenda (2008), (2009), dentre diversos outros autores.

Por um lado, verifica-se que o conhecimento disciplinar persiste e é tido por muitos como importante em todos os campos do saber. Por outro lado, verifica-se que ele é limitado em relação a algumas problemáticas novas, decorrentes, em grande parte, da maior complexidade de nossas sociedades.

De maneira geral é possível observar-se que, no pensamento interdisciplinar apresentam-se ainda grandes embates teóricos e metodológicos quanto ao seu papel e capacidade para estabelecer uma relação entre saberes, para propor o encontro entre o teórico e o prático, entre o filosófico e o científico, entre a ciência e a tecnologia.

\section{Considerações finais}

A CAPES desempenhou, e desempenha, um papel importante e decisivo na expansão da interdisciplinaridade na Pós-Graduação, acolhendo as novas iniciativas e institucionalizando-as, atribuindo-lhes prestígio e reconhecimento. Por sua vez, a política de reconhecimento e valorização da interdisciplinaridade pela CAPES tem oportunizado que instituições de ensino superior, novas ou situadas em 
regiões periféricas, expandam sua Pós-Graduação. A expansão da interdisciplinaridade também envolve as universidades mais reconhecidas como USP, UnB, UFBA, Universidade Federal de São Carlos - UFSCAR, UFRGS, UFMG e UFRJ, dentre outras. As referidas universidades realizaram recentemente vários seminários com o objetivo de aprofundar o debate sobre a importância da interdisciplinaridade, visando à implantação de políticas indutoras desta prática.

Foi possível evidenciar, neste estudo, que muitas universidades estão promovendo esforços significativos na promoção da interdisciplinaridade, mas ainda se ressentem da falta de integração em um quadro de funcionamento concebido disciplinarmente. Ressentem, igualmente, do fomento ainda tímido, e das resistências do Conselho Nacional de Pesquisa - CNPq no reconhecimento do valor da pesquisa interdisciplinar na medida em que não tem ainda definidos Comitês adequados.

$E$, no entanto, as barreiras que separam o conhecimento em compartimentos isolados estão caindo, uma após a outra. Físicos, biólogos, químicos, engenheiros, médicos e matemáticos educam-se e trocam seus saberes e competências na solução de problemas cada dia mais avançados e complexos com antropólogos, sociólogos, linguistas, neurocientistas e filósofos. As combinações de competências vão se multiplicando de forma a elaborar um novo mapa para o mundo acadêmico diante de um salto espetacular da ciência ocorrido nos últimos cem anos. A sociedade exige cada vez mais das universidades grandes esforços de mudança em sua organização e gestão. Novos modelos terão que ser criados para dar mais agilidade à produção do conhecimento, mais integração com o processo produtivo sustentável e maior internacionalização.

Contudo, mesmo figurando como um caminho possível e desejável, a interdisciplinaridade não está a salvo de riscos. Entre eles, o de se tornar uma simples justaposição de aproximações, o que a transformaria em prática pluridisciplinar. A palavra de ordem na prática interdisciplinar é o diálogo, e a forma como ele acontece define a produtiva ou a problemática interdisciplinar. É necessário, portanto, criar condições mais adequadas para a efetiva introdução da prática interdisciplinar nas instituições universitárias brasileiras.

Inúmeras questões estão ainda longe de serem resolvidas: Onde e como podemos melhor alocar os Programas de Pesquisa e Pós-Graduação Interdisciplinares nas estruturas das universidades? Como realizar concursos adequados para selecionar os docentes? Como superar a falta de profissionais no mercado de trabalho com formação interdisciplinar? Como integrar e socializar as práticas interdisciplinares bem sucedidas nos cursos de Pós-Graduação aos de Graduação? Como melhor administrar o grande crescimento do Comitê Interdisciplinar da CAPES? Qual a melhor e mais adequada estratégia para enfrentar as enormes resistências dos institutos de pesquisa vinculados ao Ministério da Ciência e Tecnologia? E, finalmente, como promover, adequadamente, sem se transformar em simples debates entre indivíduos favoráveis ou desfavoráveis, a temática da interdisciplinaridade no seio das comunidades científicas?

\section{REFERÊNCIAS}

BEVILACQUA, Luiz. Primórdios da área multidisciplinar da CAPES e suas 
influências na Pós-Graduação e na Graduação. In: PHILIPPI JR, Arlindo e SILVA NETO, Antônio. (Eds.) Interdisciplinaridade em ciência, tecnologia e inovação. Brasília/São Paulo: CAPES/Manole, p.785-802, 2011.

BORDAS, Merion C. A interdisciplinaridade na Universidade: Possibilidades e Limites. In: FRANCO, M. E.D.P. e KRAHE E. D. (Org.) Pedagogia Universitária e Áreas de Conhecimento. Porto Alegre: Série RIES-PRONEX EdiPucrs, vol. 1, p.7393, 2007.

BRASIL. CAPES - Coordenação de Aperfeiçoamento de Pessoal de Nível Superior. Documento de Área Interdisciplinar. Brasília, 2013, 85p. Disponível em <http://www.capes.gov.br/images/stories/download/avaliacaotrienal/docs_de_ar ea/ Interdisciplinar_doc_area_e_comissao_block.pdf > Acesso em: 28 fev. 2014.

BRASIL. CGEE- Centro de Gestão e Estudos Estratégicos. Doutores 2010: Estudos da demografia da base técnico-científica brasileira. Brasília, DF:, 2010, 508 p. Disponível em: < http://www.cgee.org.br>. Acesso em: 28 fev. 2014.

BRASIL. MINISTÉRIO DA EDUCAÇÃO. Análise sobre a Expansão das Universidades Federais 2003 a 2012. Brasília: DF, 2013. Disponível em: <http://portal.mec.gov.br/sesu/arquivos/pdf/diretrizesreuni.pdf>. Acesso em: 28 fev. 2014.

BRASIL. MINISTÉRIO DA EDUCAÇÃO. Diretrizes Gerais do Decreto $n^{\circ} 6.096$ REUNI - Reestruturação e expansão das universidades federais. Brasília: DF, 2007. Disponível em:

$<$ http://portal.mec.gov.br/sesu/arquivos/pdf/diretrizesreuni.pdf>. Acesso em: 28 fev. 2014.

COSTA, Helena Araújo e NASCIMENTO, Elimar Pinheiro. Benchmarking Internacional de Práticas Interdisciplinares: o caso das Universidades. In NASCIMENTO, Elimar Pinheiro do e PENA-VEGA, Alfredo. Novas dimensões da Universidade: sustentabilidade, interdisciplinaridade $e$ inserção social. Rio de Janeiro: Garamond, p.39-76, 2012.

FAZENDA, Ivani. (org.). O que é interdisciplinaridade? São Paulo: Cortez, 2008. Interdisciplinaridade: qual o sentido? São Paulo: Paulus, 2003.

1999. Interdisciplinaridade: história, teoria e pesquisa. 4. ed. Campinas: Papirus,

GUSDORF, Georges. Para uma pesquisa interdisciplinar. Diógenes, n. 7. Brasília: Editora da UnB, p.25-44, 1984.

JANTSCH, E. Vers I'Interdisciplinarité et la transdisciplinarité dans l'enseignement et l'innovation. in: L'Interdisciplinarité : Problemes d'Enseignement et de Recherche dans les Universités. Paris: CERI/OCDE, p.98-124, 1973. 
JAPIASSU, Hilton. L'épistémologie des relations interdisciplinaires dans les sciences humaines. 1975. Tese (Doutorado em Epistemologia e História das Ciências) - Faculdade de Filosofia, Université des Sciences Sociales de Grenoble (França), Grenoble.

JAPIASSU, Hilton. Interdisciplinaridade e patologia do saber. Rio de Janeiro: Imago, 1976.

O sonho transdisciplinar. Rio de Janeiro: Imago, 2006.

KLEIN, Julie Thompson. Crossing boudaries: knowledge, disciplinarities, and interdisciplinarities. Virginia: University Press of Virginia, 1996.

Interdisciplinarity: History, Theory \& Pratice. Detroit: Wayne State University Press, 1990.

KLEIN, Julie Thompson. The Broad Scope of Interdisciplinarity. In: D.E. Chubin, A.L. Porter, F. A. Rossini e T. Connolly (Eds.), Interdisciplinary Analysis and Research. Maryland: Lomond, p.409-424, 1986 b.

KLEIN, Julie Thompson. The Dialectic and Rhetoric of Disciplinarity and Interdisciplinarity. In: D. E. Chubin, A. L. Porter, F. A. Rossini e T. Connolly (Eds.), Interdisciplinary Analysis and Research. Maryland: Lomond, p.85-100, 1986a.

MORIN, Edgar A cabeça bem feita. Repensar a reforma, repensar o pensamento. 6 ed., Rio de janeiro: Bertrand Brasil, 2002.

MORIN, E. Ciência com consciência. Rio de Janeiro: Bertrand Brasil, 2000.

MORIN, Edgar Os Sete Saberes necessários à Educação do Futuro. 2. ed. São Paulo: Cortez, 2000. Parâmetros Curriculares Nacionais: Ensino Médio. Ministério da Educação. Brasília, 1999.

NASCIMENTO, Elimar Pinheiro; PENA-VEGA, Alfredo (orgs). As novas dimensões da universidade: Interdisciplinaridade, sustentabilidade e inserção social. Rio de Janeiro: Garamond, 2012.

PHILIPPI JR. A; SILVA NETO, A. J. (org) Interdisciplinaridade em ciência, tecnologia \& inovação. Barueri, SP: Manole, 2011.

PIAGET, Jean. "L'epistemologie des relations interdisciplinaires". In: APOSTEL, Leo e col. (Orgs). L'interdisciplinarité : problemes d'enseignement et de recherche dans les universités. Rapport du Séminaraire sur l'Interdisciplinarite, Nice, 1970. Paris: CERI - Centre pour da Recherche et I'Innovations das I'Enseignement/OCDE - Organisation de Coopération et de Développement Économiques, p.131-144, 1973. 
POMBO, O. Práticas interdisciplinares. Sociologias, v.8, n.15, p.208-249, junho 2006.

REPKO, A.F. Interdisciplinary reseach: process and theory. Thousand Oaks: Sage, 2008.

SANTOS, Boaventura de Sousa. A Crítica da Razão Indolente: Contra o Desperdício da Experiência. São Paulo: Cortez, 2000.

Um Discurso sobre as Ciências. São Paulo: Cortez, 2003.

SOMMERMAN, Américo. A interdisciplinaridade e a transdisciplinaridade como novas formas de conhecimento para a articulação de saberes no contexto da ciência e do conhecimento em geral: contribuição para os campos da educação, da saúde e do meio ambiente. Tese (Doutorado Multidisciplinar e Multi-institucional em Difusão do Conhecimento) - Universidade Federal da Bahia. Salvador, 2012.

Submetido em 22/06/2014

Aprovado em 07/12/2015

\section{Sobre os autores}

\section{Elvio Quirino Pereira}

Pós-doutorando do Centro de Desenvolvimento Sustentável - CDS/UnB, Doutor em Sociologia e Professor associado da Universidade Federal do Tocantins - UFT. Endereço para correspondência: 204 Sul, Alameda: 03, Lote: 03, Residencial Tereza Ayres, Apartamento: 602. 77.020.502 Palmas -TO - Brasil.

E-mail: elvio@uft.edu.br.

\section{Elimar Pinheiro do Nascimento}

Sociólogo, doutor em sociologia pela Universidade René Descartes, Paris $V$, professor associado do Centro de Desenvolvimento Sustentável da Universidade de Brasília - CDS/UnB.

Endereço para correspondência. Rua Espirito Santo, 14. Vila Planalto. 70803.260 - Brasilia - DF Brasil.

E-mail: elimarcds@gmail.com 